\title{
Prevalence of sensorineural hearing loss among medical students who are chronic mobile phone and earphone users in Trivandrum, South Kerala, India
}

\author{
Ceepa Ann Thomas ${ }^{1}$, Rejee Ebenezer ${ }^{2}$, Y. Suba Joice ${ }^{3 *}$ \\ ${ }^{1}$ Intern, ${ }^{2}$ Professor and Head, ${ }^{3}$ Associate Professor, ${ }^{2}$ Dept. of ENT, ${ }^{3}$ Dept. of Community Medicine, Dr. Somervell Memorial CSI Medical \\ College, Karakonam, Kerala, India
}

*Corresponding Author: Y. Suba Joice

Email: suba_joice@yahoo.com

\begin{abstract}
Introduction: Hearing loss occurs as age increases, but these days seen affecting young adults as well. This could be due to the current increasing trend of chronic usage of personal listening devices (PLDs) such as mobile phones and earphones, which causes damage to the inner hair cells of the ear.

Objectives: To study the prevalence of chronic PLD users among medical students and to assess the proportion of sensorineural hearing loss among them. To assess the perceived effects of listening to PLDs among chronic and non-chronic users of PLDs in medical students.

Materials and Methods: A cross sectional study was done among 420 medical students of Dr. Somervell Memorial CSI Medical College in 2016. Basic information was collected from each student using a self administered predesigned and pretested questionnaire and chronic users were selected and subjected to pure tone audiometry and otoacoustic emissions (OAE).

Results: Of the 420 students consented for the study, $44 \%$ were chronic users of PLDs. 120 students were subjected to audiometry and OAE. The total prevalence of sensorineural hearing loss was found to be $5 \%$ with high frequency hearing loss and $18.3 \%$ for low frequency hearing loss OAE results were normal in all individuals. The main associated complaints were poor academic performance, lack of sleep, limb pain and road side accidents.

Conclusion: This study concluded only mild degree sensorineural hearing loss among chronic users of PLDs. However the associated complaints such as poor academic performance and roadside accidents were comparatively more in chronic users than non-chronic users.
\end{abstract}

Keywords: India, Kerala, Medical students, Personal listening devices (PLDs), Sensorineural hearing loss.

\section{Introduction}

Hearing, one of the five senses, is the complex process of picking up sound and attaching meaning to it. The human ear is fully developed at birth and hence very faint as well as loud sounds can be appreciated and responded to very well ${ }^{1}$ However hearing decreases with age and due to continuous exposure to environmental noise such as television sounds, traffic, construction sites, industrial appliances etc. Thus noise is defined as an unwanted or unpleasant sound. ${ }^{1}$

As hearing loss is a natural phenomenon with age, most commonly thought to be seen in the elderly, now a days it is also common in younger people due to the frequent usage of mobile phones and earphones. ${ }^{2}$ Since centuries ago music has been one of the main forms of entertainment, whether it is for dances, concerts, functions, and radios. The genre and style of music is countless thus the admirers and lovers of music. From radios to mp3 players to music in cell phones the listeners of music have tremendously grown, especially since the availability and affordability have increased. From speakers to earphones/headphones have the trend traveled, enabling students with chaos work schedules to listen to music during free hours, travelling, or for stress relief. ${ }^{2}$ The dangers of music-induced hearing loss however are seldom looked upon. When people are exposed to harmful noise for a prolonged duration of time, the hair cells present in the inner ear are damaged causing noise-induced-hearing loss (NIHL). ${ }^{1}$ The hair cells (sensory cells) convert sound energy into electrical signal which reaches the auditory processing center in the brain. Once damage is caused to these cells, regeneration is not attainable. ${ }^{1}$
Music has evolved over the decades, so has the manner of communication between individuals residing in wide geographic areas. ${ }^{2}$ From letters to telephones to cell phones have the communication of ideas, special moments, and events conveyed. Along with being able to talk to an individual, text messaging, e-mail, internet access, and other business application, gaming, and photography has taken its root. Thus the facilities through smart phones have increased. ${ }^{2}$ For the past 20 years the mobile phone usage have increased from 12.4 million to over 5.6 billion thus forming $70 \%$ of the world population. The sizeable number of users were school and college going students. ${ }^{2}$

As about $87-90 \%$ of population in developed countries like USA use cell phones, the scenario is similar with people of India. The educated as well as the illiterate and people belonging to all age groups are daily dependent on cell phones for their day to day activities. Most phones that emit electromagnetic radiation reach the public without any prior safety testing. ${ }^{3}$ Thus the radio frequency fields from mobile phones could affect the hearing of individuals. ${ }^{4}$ The use without any prior knowledge to its harmful effects is lethal. Not only does the constant usage for a prolonged duration of time cause sensorineural hearing loss, but it can also have an effect on people physically and psychologically. ${ }^{3}$ Exposure to loud noise can lead to hearing impairment as personal audio electronics such as mobile phones and headsets can produce sounds up to $120 \mathrm{db}$ which is injurious to hearing. ${ }^{1}$ Thus we decided to conduct a study among personal listening devices using medical students of Dr. SMCSI Medical College. 


\section{Objectives}

Primary objectives: To study the prevalence of chronic Personal listening device users among medical students and to assess the proportion of sensorineural hearing loss among medical students who are chronic mobile phone, and earphone/headset users. Secondary objectives: To assess the type and degree of hearing loss and the perceived effects of listening to PLDs among chronic and non-chronic users of PLDs among medical students.

\section{Materials and Methods}

A cross-sectional study was conducted among undergraduate medical students of Dr. Somervell Memorial CSI Medical College and Hospital, Karakonam in Trivandrum district of Kerala state in South India from December 2015 - October 2016 of which two months June - July 2016 was used for data collection. Using the prevalence of $18 \%$ medical students who self reported to be chronic PLDs users as per the criteria of using PLDs continuously for more than 1 hour duration per day (Unpublished data from dept of Community Medicine), considering an error of $20 \%, 455$ undergraduate medical students were required to conduct this study. Students from 2012 to 2016 batches were available in the campus during the data collection period. Each batch the intake of students were 100. Of the available students in the campus only 420 students consented to participate in the study. Thus the nonresponse rate was $7.7 \%$. Medical students who didn't give consent and students with previous history of ear discharge, ear surgeries, or any other illness, diseases, states or events that are contributing to ear disease, hard of hearing, or sensorineural hearing loss were excluded from the study. Written permission was obtained from the principal of the institution and the study was conducted only after obtaining Institutional Ethics Committee clearance (No.SMCSIMCH/EC(PHARM)8/2016 dated 26.05.2016). After explaining the purpose of the study a written informed consent was obtained from all the students who were willing to participate in the study. Using a predesigned and pretested self administered structured questionnaire sociodemographic details and use and associated symptoms with personal audio electronics (mobile phones/headphones) were collected. Among these students, only students who were using PLDs for more than 1 hour duration continuously per day were considered as chronic users. Those students identified as chronic users were then subjected to pure tone audiometry and otoacoustic emissions to detect and grade the degree of sensorineural hearing loss. Both pure tone audiometry and Otoacoustic emission test was performed to the students by trained audiometrist from department of ENT. The fund for performing the test was provided from Comprehensive Rehabilitation Project working for differently abled people in the community supported by Christophel Blinden Mission. The data thus collected was entered in excel and analyzed using SPSS Software trial version 16.0. All quantitative variables were analyzed for mean and standard deviation. All qualitative variables were analyzed for proportions. Odds ratio was done to assess the perceived effects of listening to PLDs among chronic and non-chronic users of PLDs among medical students. The study would benefit the students by creating awareness about the hazards of chronic mobile phone usage as in sensorineural hearing loss, physical trauma, and psychological illness. It would facilitate early detection and prevention of sensorineural hearing loss in young age groups. Any student identified with defect will be counseled and treated appropriately by experts from the department of ENT.

\section{Results}

420 undergraduate medical students participated in the study. The mean age of the students were $20.6 \pm 1.55$ years, ranging from 17 to 26 years. $65.5 \%$ were females, and $34.5 \%$ males. The participants mostly consisted of $1^{\text {st }}$ years, about $47.6 \%, 2^{\text {nd }}$ years $20.5 \%, 3^{\text {rd }}$ years $17.4 \%$, and $4^{\text {th }}$ years $13.8 \%$, and $0.7 \%$ interns. (Table 1). The Participants were considered as chronic PLDs users if there was continuous usage of either mobile phones or headphones for more than 1 hour per day. $44 \%$ of the participants were found to be chronic PLDs users. (Table 2).

Pure tone audiometry was done on 120 students who were identified as chronic users $(65 \%)$. The limitation found in data collection was few students could not make up for audiometry and OAE testing due to exams and other personal reasons. Also the busy hospital work hours and the afternoon time allotted for the testing as well as the number of students those could be tested each day within the 2 months for actual data collection was at interference. Thus high frequency hearing loss was very minimal as no hearing loss was detected at $1 \mathrm{~K}$ and $2 \mathrm{~K}$, while only $0.8 \%$ loss was found in the right ear at $4 \mathrm{~K}$, and $1.7 \%$ in the left ear. $8 \mathrm{~K}$ findings were $1.7 \%$ in right ear, and $2.5 \%$ in left ear. However table 3 shows minimal low frequency hearing loss among medical students. In $250 \mathrm{~Hz} \mathrm{5 \%}$ hearing loss was found in the right and left ear. In $500 \mathrm{~Hz} 12.5 \%$ had hearing loss in the right ear, and $7.5 \%$ had hearing loss in the left ear. (Table 3)

Considering the degree of hearing loss based on pure tone audiometry findings frequencies $\geq 4 \mathrm{KHz}$ was considered as high frequency hearing loss and frequencies $<4 \mathrm{KHz}$ as low frequency hearing loss. Thus among the 120 Chronic PLDs users of medical students prevalence of hearing loss was found among $22 \%$. However $4 \%$ of students were found to have high frequency hearing loss and $22 \%$ of the students had low frequency hearing loss. (Table 4)

Bone conduction test was done in all the students that showed sensorineural hearing loss. In high frequencies only $2.5 \%$ had a dip in bone conduction at $4 \mathrm{~K}$, while in low frequencies $5 \%$ had dip in $250 \mathrm{~Hz}$, and $9.2 \%$ had dip in $500 \mathrm{~Hz}$. (Table 5)

All $120(100 \%)$ of the medical students who were chronic mobile phone users subjected to otoacoustic emissions passed it which means that the cochlear status was found normal. 
Considering the perceived symptoms associated with chronic PLDs usage, it was found that poor academic performance was found more in chronic users $15.7 \%$ than non chronic users only $6.4 \%$, the chronic users are 2.73 times more at risk than non users and this finding is statistically significant (CI -1.42-5.26). The other symptom is lack of sleep, $5.5 \%$ in non chronic users, and $17.8 \%$ in chronic users, and they are 3.71 times more at risk than non users and it is statistically significant (CI- 1.89-7.28). Neck pain was another perceived risk factor of 1.76 times seen more in chronic users $(17.3 \%)$ than in non chronic users $(10.6 \%)$ and this was near to statistical significance (CI-
1.00-3.09). Limp pain was also complained by students due to mobile phone and ear phones uses, as $4.9 \%$ of chronic users complained more than $1.3 \%$ of non users, and chronic users being at 3.96 greater risk of getting limp pain, and this was also found to be statistically significant (CI- 1.0614.82). Another great event and risk factor that can been seen in the results are the occurrence of road side accidents due to lack of awareness due to the usage of PLDs, there is 6.66 times more risk seen in chronic users $(5.4 \%)$ than non chronic users $(0.9 \%)$ this is statistically significant as well(CI- 1.44-3.77).(Table 6)

Table 1: Socio-demographic characteristics of the medical students $(n=420)$

\begin{tabular}{|c|c|c|}
\hline $\begin{array}{c}\text { Socio-demographic Characteristics of } \\
\text { medical students }\end{array}$ & Frequency & Percentage (\%) \\
\hline Age in Years (Mean \& SD) & \multicolumn{2}{|c|}{$20.6(1.55)$} \\
\hline Gender & 145 & 34.5 \\
Male & 275 & 65.5 \\
Female & 200 & 47.6 \\
\hline Education & 86 & 20.5 \\
$1^{\text {ST }}$ Years & 73 & 17.4 \\
$2^{\text {nd }}$ years & 58 & 13.8 \\
$3^{\text {rd }}$ years & 3 & 0.7 \\
$4^{\text {th }}$ years & & \\
Interns & & \\
\hline
\end{tabular}

Table 2: Proportion of Chronic users of PLDs among the study participants $(\mathrm{N}=420)$

\begin{tabular}{|c|c|c|}
\hline Type of PLD users based on duration of use & Frequency & Percentage (\%) \\
\hline Chronic users $(>1 \mathrm{hr})$ & 185 & 44 \\
\hline Non Chronic Users $(<1 \mathrm{hr})$ & 235 & 56 \\
\hline Total & 420 & 100 \\
\hline
\end{tabular}

Table 3: Prevalence of Sensorineural hearing loss among Chronic PLDs using medical students based on Pure tone audiometry findings ( $\mathrm{N}=120)$

\begin{tabular}{|c|c|c|}
\hline $\begin{array}{c}\text { Hearing loss based on Pure tone } \\
\text { audiometry in hertz }\end{array}$ & Right ear Frequency (\%) & Left ear Frequency (\%) \\
\hline $250 \mathrm{~Hz}$ & $6(5.0)$ & $6(5.0)$ \\
\hline $500 \mathrm{~Hz}$ & $15(12.5)$ & $9(7.5)$ \\
\hline $1 \mathrm{~K}$ & 0 & 0 \\
\hline $2 \mathrm{~K}$ & 0 & 0 \\
\hline $4 \mathrm{~K}$ & $1(0.8)$ & $2(1.7)$ \\
\hline $8 \mathrm{~K}$ & $2(1.7)$ & $3(2.5)$ \\
\hline
\end{tabular}

Table 4: Prevalence of Sensorineural hearing loss in terms of high and low frequency among Chronic PLDs using medical students based on Pure tone audiometry findings $(\mathrm{N}=120)$

\begin{tabular}{|c|c|}
\hline Frequency of hearing loss & Present n $(\%)$ \\
\hline High frequency $(\geq 4 \mathrm{~K})$ & $5(4.2)$ \\
\hline Low frequency $(<4 \mathrm{~K})$ & $21(17.5)$ \\
\hline Total & $26(21.6)$ \\
\hline
\end{tabular}

Table 5: Prevalence of hearing loss among Chronic PLDs using medical students based on Bone conduction test $(\mathrm{N}=120)$

\begin{tabular}{|c|c|c|}
\hline Hearing loss based on Bone conduction test in decibels & Frequency & Percentage \\
\hline $250 \mathrm{~Hz}$ & 6 & 5 \\
\hline $500 \mathrm{~Hz}$ & 11 & 9.2 \\
\hline $1 \mathrm{~K}$ & 0 & 0 \\
\hline $2 \mathrm{~K}$ & 0 & 0 \\
\hline $4 \mathrm{~K}$ & 3 & 2.5 \\
\hline
\end{tabular}


Table 6: Perceived effects of listening to PLDs among the study participants $(n=420)$

\begin{tabular}{|c|c|c|c|c|}
\hline Perceived Symptoms/ risks & $\begin{array}{c}\text { Chronic users } \\
(\mathbf{n = 1 8 5})\end{array}$ & $\begin{array}{c}\text { Not chronic users } \\
(\mathbf{n = 2 3 5})\end{array}$ & Odds ratio & 95\% CI \\
\cline { 2 - 3 } & Frequency (\%) & Frequency (\%) & & \\
\hline Headache & $49(26.5)$ & $69(29.5)$ & 0.87 & $0.56-1.33$ \\
Migraine & $15(8.1)$ & $11(4.7)$ & 1.80 & $0.81-4.01$ \\
Irritability & $27(14.6)$ & $23(9.8)$ & 1.58 & $0.87-2.85$ \\
Lack of concentration & $42(22.7)$ & $39(16.6)$ & 1.48 & $0.91-2.40$ \\
Lack of academic performance & $29(15.7)$ & $15(6.4)$ & 2.73 & $1.42-5.26$ \\
Lack of sleep & $33(17.8)$ & $13(5.5)$ & 3.71 & $1.89-7.28$ \\
Fatigue & $15(8.1)$ & $10(4.3)$ & 1.99 & $0.87-4.53$ \\
Tiredness & $26(14.1)$ & $23(9.8)$ & 1.51 & $0.83-2,74$ \\
Loss of appetite & $7(3.8)$ & $6(2.6)$ & 1.50 & $0.50-4.54$ \\
Neck Pain & $32(17.3)$ & $25(10.6)$ & 1.76 & $1.00-3.09$ \\
Limp pain & $9(4.9)$ & $3(1.3)$ & 3.96 & $1.06-14.82$ \\
Back Pain & $14(7.6)$ & $17(7.2)$ & 1.05 & $0.50-2.19$ \\
Tinnitus & $15(8.1)$ & $12(5.1)$ & 1.64 & $0.75-3.59$ \\
Road side accidents & $10(5.4)$ & $2(0.9)$ & 6.66 & $1.44-3.77$ \\
\hline
\end{tabular}

\section{Discussion}

This study was conducted to evaluate the sensorineural hearing loss among medical students who are chronic mobile phone and ear phone users and the associated symptoms that pertained to PLDs usage. The age groups selected for this study were medical students between 17-26 years, the mean age being 20.6 years. Similar studies were done in Uttar Pradesh, and Karnataka with medical students of both genders and age group of 15-25 years and 18-30 yrs respectively. ${ }^{5,4}$ Both these studies concluded that significant hearing loss was not found among these age groups. The normal values in both these studies for hearing loss were taken as below $25 \mathrm{~dB}$. In our study, out of 420 students participated, 120 audiometry and OAE was done, in that high frequency hearing loss was considerably less than anticipated, as no individuals had hearing loss at $1 \mathrm{k}$ or $2 \mathrm{k}$, but $0.8 \%$ (right ear) dip $1.7 \%$ (left ear) was seen in $4 \mathrm{~K}$. In 8 K $1.7 \%$ (right ear) and $2.5 \%$ (left ear) was seen. The other findings were for low frequencies that is for $250 \mathrm{~Hz}$ (Right/Left ear) $5 \%$ and $500 \mathrm{~Hz}$, right ear with $12.5 \%$ loss, and left ear $7.5 \%$ loss. These findings in low frequency could have been due to any other underlying pathology or due to any external disturbances. A study done in Tamil Nadu with age groups of 20-45yrs, sensorineural hearing loss was found with $3 \%$ prevalence. ${ }^{6}$ However in their study they included individuals that gave symptoms of vertigo, ear discomfort, and fullness of the ear, which could have attributed to the hearing loss, while our study excluded individuals who gave history of vertigo, ear discomfort, family history of hearing loss, individuals on oto-toxic drugs, fullness of ear, any ear block with wax, or any other underlying ear pathology.

The individuals were assessed on chronic usage of PLDs, that is usage for more than 1 hour per day, our findings was that non chronic users $(56 \%)$ were more than chronic users $(44 \%)$. This results were contrary to results obtained in the study done in Mangalore ${ }^{7}$ where $77.7 \%$ were chronic users.
The associated symptoms pertaining to the use of PLDs revealed the highest risk factors were students complaining of poor academic performance among chronic users $(15.7 \%)$ compared to non chronic users (6.4\%). The other risk factor being lack of sleep (17.8\%) in chronic users was much more than $5.5 \%$ in non chronic users. Another physical symptom seen is neck pain and limp pain due to the usage of PLDs. Road side accidents were also common due to the lack of environmental awareness being $(5.4 \%)$ and only $(0.9 \%)$ in non chronic users that is 6.66 times more risk factor is seen in chronic users than in non chronic users. This data is supported by a study done in Hyderabad where in general the symptoms were assessed and $51.47 \%$ had headache, irritability $(50.79 \%)$, Lack of concentration $47.4 \%$, Poor academic performance, insomnia $(35.4 \%)$, tiredness $(32.7 \%)$, and physical symptoms such as body ache etc $(32.19 \%)^{3}$

Otoacoustic emissions were done for all the 120 individuals and they all passed which was in good correlation to the study done in Germany, where 88 subjects influenced by leisure-time noise exhibited no measurable pure tone hearing loss. ${ }^{8}$

\section{Conclusion}

455 medical students were enrolled in this study out of which 420 responded, thus with the non responsive rate of 7.7\%. Among 420 students, 185 students were chronic PLDs users and $120(64.8 \%)$ of them were subjected for audiometry and OAE. $4 \%$ of students were found to have high frequency hearing loss and $22 \%$ of the students had low frequency hearing loss. All the subjects fell under the pass category for OAE. The main associated symptoms were lack of academic performance, irritability, lack of sleep, neck pain, limb pain, and history of accidents in road environments among chronic users compared to non-chronic users of PLDs. 


\section{Acknowledgements}

We take this opportunity to thank the Principal of Dr. SMCSI Medical College for giving us the permission to conduct this study. We also thank the ICMR for providing approval and fund for this STS-2016 project. We also thank the director of Comprehensive Rehabilitation project supported by cbm working for differently abled people for granting funds for the conduct of audiometry in identification of sensorineural hearing loss among medical students. A special thanks to all the students from 2012 to 2016 batches who participated in this study. Our sincere thanks to Ms. Akhila, audiologist in Dept. of ENT for her overtime stay and help rendered in data collection.

\section{Conflict of Interest: None.}

\section{References}

1. S.E. Ogbe, M.B. Akor-Dewu, M.I. Saleh, E.D. Eze, O.Olufunke, A. Shaibu et al, Effects of headphones on hearing acuity of students of Ahmadu BelloUniversity, Zaria, Nigeria. Annals Biol Sci 2014, 2(1):7-9.

2. Naik K, Pai S. High frequency hearing loss in students used to ear phone music: A randomized trial of 1,000 students. Indian J Otol 2014;20:29-32.
3. Acharya JP, Acharya I, Waghrey D. A Study on Some of the Common Health Effects of Cell-Phones amongst College Students. J Community Med Health Educ 2013;3:214.

4. Hegde MC, Shenoy VS, Kamath PM, Rao RA, Prasad V, Varghese BS et al. Mobile phones: Its effect on hearing. Indian J Otol 2013;19:122-6.

5. Mohan C., Bhardwaj P., Srivastava A. Manifestations of mobile use in young adults. Orlonline 2014;4(4).

6. GC Sahoo, Honeymol Sebastian. Prevalence of sensorineural deafness in habitual mobile phone users. Indian J Otol 2011;17:97-100

7. Rekha T, Unnikrishnan B, Mithra PP, Kumar N, Bukelo MJ, Ballala K. Perceptions and practices regarding use of personal listening devices among medical students in coastal South India. Noise Health 2011;13:329-32

8. Rosanowski, F., Eysholdt, U. \& Hoppe, U. Int Arch Occup Environ Health 2006;80:25.

How to cite this article: Thomas CA, Ebenezer R, Joice YS. Prevalence of sensorineural hearing loss among medical students who are chronic mobile phone and earphone users in Trivandrum, South Kerala, India. Indian J Forensic Community Med 2019;6(2):81-85. 